\title{
Electrochemical Behaviour of Tinidazole at 1,4-Benzoquinone Modified Carbon Paste Electrode and Its Direct Determination in Pharmaceutical Tablets and Urine by Differential Pulse Voltammetry
}

\author{
Yosef Nikodimos and Beyene Hagos \\ Department of Chemistry, Woldia University, P.O. Box 400, Woldia, Ethiopia \\ Correspondence should be addressed to Yosef Nikodimos; yosefni2001@gmail.com
}

Received 20 April 2017; Revised 10 August 2017; Accepted 24 August 2017; Published 7 November 2017

Academic Editor: Sibel A. Ozkan

Copyright (C) 2017 Yosef Nikodimos and Beyene Hagos. This is an open access article distributed under the Creative Commons Attribution License, which permits unrestricted use, distribution, and reproduction in any medium, provided the original work is properly cited.

\begin{abstract}
A simple and highly sensitive electrochemical method based on a 1,4-benzoquinone modified carbon paste electrode (1,4BQMCPE) was described for the determination of tinidazole (TDZ). In Britton Robinson buffer solution, TDZ yields well-defined irreversible reduction peak at $-0.344 \mathrm{~V}$ on a 1,4 -BQMCPE. Compared with that on a bare CPE, the reduction peak of TDZ increased significantly on the modified CPE and the effects of different parameters on the voltammetric responses were also investigated. Differential pulse voltammetric method was proposed and optimized for TDZ determination and its reductive peak current response at 1,4-BQMCPE was found to show linear dependence on the concentration of TDZ in the range of $1.0 \times 10^{-6}$ to 5.0 $\times 10^{-4} \mathrm{M}$ with a linear regression equation, correlation coefficient, limit of detection (LOD), and limit of quantification (LOQ) of $I_{\mathrm{PC}}(\mu \mathrm{A})=0.19958+0.02657 \mathrm{C}(\mu \mathrm{M}), 0.99486,1.10 \times 10^{-7} \mathrm{M}$, and $3.77 \times 10^{-7}$, respectively. Excellent recovery results for spiked TDZ in pharmaceutical tablet samples ranging within $97.44-97.51 \%$ and in urine ranging within $95.37-96.91 \%$ were observed. The selectivity of the method for TDZ was further studied in the presence of selected potential interferents and confirmed the potential applicability of the developed method for the determination of TDZ.
\end{abstract}

\section{Introduction}

TDZ, $\mathrm{C}_{8} \mathrm{H}_{13} \mathrm{~N}_{3} \mathrm{O}_{4} \mathrm{~S}$, which is 1-(2-ethyl sulfonyl ethyl)-2methyl-5-nitro-imidazole derivative, an antiparasitic drug, is used as an antiprotozoal drug (molecular weight: $247.273 \mathrm{~g} /$ mol). It is highly effective for bacterial [1-3] and protozoan [3] infections and is available in the tablet form.

TDZ is an antiparasitic drug used against protozoan infections, bacterial infections, infections of the blood, lungs infection, chest infections, skin infections, womb lining infections, gums infection, vaginal or stomach infections, and others. It is widely known throughout the world as a treatment for a variety of amoebic and parasitic infections. A large body of clinical data exists to support its use as a treatment for amebas, giardia, and vaginal trichomoniasis [1-5].
Taking into account its importance, the determination of TDZ has a great importance. Many methods have been developed and applied in the detection of TDZ like electrochemical techniques [6-10], titrimetric [11], spectrophotometry [11$17]$, and HPLC $[12,16,18-22]$.

Since most of the conventional methods reported need trained personnel to operate and are expensive and not environmentally friendly, the development of another alternative electrochemical method which is selective, sensitive, cheap, and environmentally friendly is necessary.

In recent years, polymer-modified electrodes have received attention due to their good stability, reproducibility, increase in active sites, homogeneity in electrochemical deposition, and strong adherence to electrode surface [23]. The benzoquinone modified electrodes had shown 
remarkable advantages from their low noise levels and higher sensitivity [24].

This paper describes voltammetric method for determination of TDZ via its reduction at a 1,4-benzoquinone modified carbon paste electrode (1,4-BQMCPE). The electrode process was investigated by cyclic voltammetry $(\mathrm{CV})$ and differential pulse voltammetry (DPV). The influence of different experimental parameters such as $\mathrm{pH}$, accumulation time, and scan rate was investigated to optimize the proposed method. The method is successfully applied for the determination of TDZ in pharmaceutical tablets and urine, and the results obtained were compared with earlier reported method.

\section{Experimental Part}

2.1. Apparatus and Reagents. BAS $100 \mathrm{~B}$ electrochemical analyzer [Bioanalytical Systems (BAS), USA] connected to a personal computer was used for the voltammetric measurements. A three electrodes' system consisting of 1,4-BQMCPE as working electrode, platinum coil as auxiliary electrode, and $\mathrm{Ag} / \mathrm{AgCl}$ as reference electrode was used. The $\mathrm{pH}$ of the buffer solutions was measured with Jenway model $3310 \mathrm{pH}$ meter. An electronic balance (Denver instrument) was used for measuring mass of different chemicals and samples. A magnetic stirrer with a hot plate was used for stirring during $\mathrm{pH}$ adjustments.

Standard TDZ (Emmelen Biotech Pharmaceuticals Limited) and TDZ tablet of different brands (APF and EPHARM) were used. Graphite powder (BDH-Laboratory Supplies, Poole, England), paraffin oil (Abron Chemicals), boric acid (BIO-lab laboratories LTD), phosphoric acid (Veeni Chemicals), glacial acetic acid and $\mathrm{NaOH}$ (supplied by Blulux laboratories reagent), $\mathrm{HCl}$ (BDH Limited, Poole, England), and 1,4-benzoquinone (Riedel-De Haen, Germany) were used in the experiment. Distilled water was used throughout the work.

\subsection{Procedures}

2.2.1. Preparation of TDZ Standard Solutions. 0.01 molar stock solution of TDZ was prepared by dissolving 0.247 grams of standard TDZ in $100 \mathrm{~mL}$ of $5 \%$ of ethanol with water. Tinidazole (see Scheme 1) working solutions were prepared by diluting the stock solution with the BRB buffer solutions of the required $\mathrm{pH}$. The supporting electrolyte Briton Robinson buffers (BRB) in the $\mathrm{pH}$ range 2.0-7.0 were prepared from $\mathrm{H}_{3} \mathrm{BO}_{4}, \mathrm{CH}_{3} \mathrm{COOH}$, and $\mathrm{H}_{3} \mathrm{PO}_{4}$ each with 0.04 molar in distilled water. $1.0 \mathrm{~mol} \mathrm{~L}^{-1} \mathrm{NaOH}$ and $1.0 \mathrm{~mol} \mathrm{~L}^{-1} \mathrm{HCl}$ solutions were used to adjust the $\mathrm{pH}$ of the buffer solution.

2.2.2. Preparation of Pharmaceutical Tablet Samples. TDZ tablets (EPHARM and APF) were purchased from pharmacy. Tablets (labeled as $500 \mathrm{mg}$ TDZ/tablet) of pharmaceutical formulations were accurately weighed and finely powdered in a porcelain mortar. 0.296 grams of this powder, corresponding to a stock solution of concentration 0.01 molar, was weighed and transferred into a $100 \mathrm{~mL}$ flask and dissolved

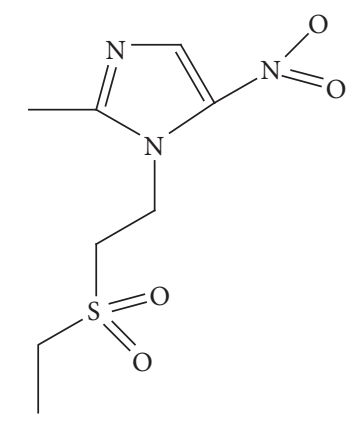

Scheme 1: Structure of tinidazole.

with $5 \%$ of ethanol solution. The tablet solutions were filtrated using a Whatman ${ }^{\circledR}$ filter paper. Then, 50.0 and $90 \mu \mathrm{M}$ sample solutions were prepared from the stock solution using 0.04 molar BRB solutions for each TDZ tablet brand.

2.2.3. Preparation of TDZ Solution in Urine. The urine sample was taken from a volunteer healthy individual immediately before the experiments. The urine sample was suction filtrated using a $0.45 \mu \mathrm{m}$ pore size filter paper. The filtrate was then diluted with $\mathrm{pH} 5 \mathrm{BRB}$ solution in a 1:4 volume ratio. Then, $90 \mu \mathrm{M}$ solutions were prepared from the different brands of TDZ tablets using the diluted filtrated urine.

2.2.4. Preparation of Working Electrodes. Unmodified carbon paste electrode (CPE) (100 mg) was prepared by mixing graphite powder with paraffin oil. The composition of the paste was $75 \%(\mathrm{w} / \mathrm{w})$ graphite powder and $25 \%(\mathrm{w} / \mathrm{w})$ paraffin oil. The mixture was homogenized with mortar and pestle for 30 minutes and allowed to rest for 24 hours. The homogenized paste was packed into the tip of a plastic syringe $(3 \mathrm{~mm}$ diameter, $7 \mathrm{~mm}$ deep). A copper wire was inserted from the backside of the syringe to provide electrical contact. Then the surface of the electrode was smoothed against a smooth white paper with a light manual pressure until a shiny surface is emerged.

Modified carbon paste $(100 \mathrm{mg})$ was prepared by mixing graphite powder with 1,4- benzoquinone in paraffin oil. To $10 \mathrm{mg}$ of 1,4-benzoquinone and $70 \mathrm{mg}$ of carbon powder initially mixed with a mortar and pestle for 5 minutes, $23 \mu \mathrm{L}$ $(20 \mathrm{mg})$ of paraffin oil was added and thoroughly mortared together for 30 minutes. The resulting paste was packed into the tip of the syringe by extruding a small amount of paste from the tip of the previously prepared unmodified carbon paste electrode.

2.2.5. Electrochemical Procedure. Both the $\mathrm{Ag} / \mathrm{AgCl}$ reference and Pt auxiliary electrodes were rinsed with distilled water prior to each measurement. The surface of the 1,4BQMCPE was also smoothed manually against a smooth white paper. Voltammetric measurements were recorded using 1,4-BQMCPE working electrode after a stable voltammogram was obtained in BRB solution.

Cyclic voltammetric measurements were recorded and the influence of $\mathrm{pH}$ on the net peak current of TDZ was 


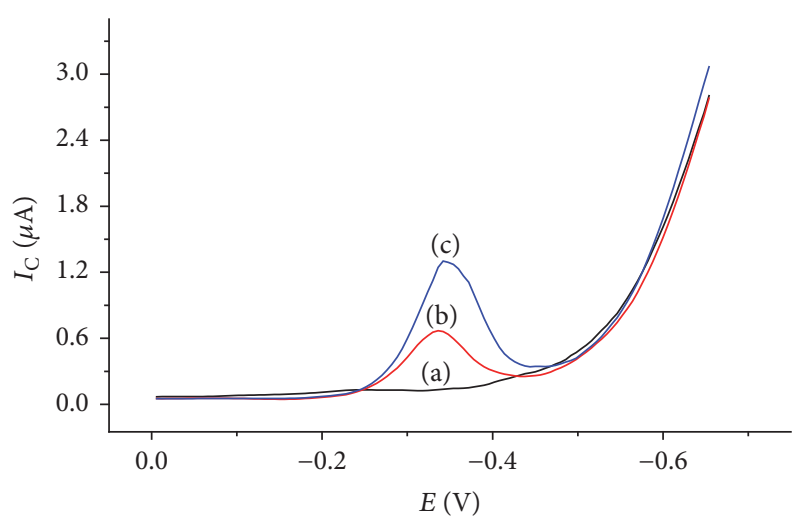

FIgURE 1: Cyclic voltammograms of (a) CPE in BRB solution containing no TDZ, (b) CPE in BRB solution containing $0.5 \mathrm{mM}$ TDZ, and (c) 1,4-BQMCPE in BRB solution containing $0.5 \mathrm{mM}$ TDZ; scan rate: $100 \mathrm{mV} \mathrm{s}^{-1}$; potential window: 0 to $-700 \mathrm{mV}$.

investigated over $\mathrm{pH}$ range of 2.0-7.0. The effect of scan rate on both the reductive peak current and peak potential was investigated in the range 20 to $200 \mathrm{mVs}^{-1}$. Furthermore, differential pulse voltammetry was used for the quantitative determination of TDZ in pharmaceutical samples. After a calibration curve was constructed using external standard addition of TDZ solutions of different concentrations, the regression equation was used for the determination of the TDZ content in tablets of different brands. Recovery results of spiked standard TDZ in tablet solutions and urine and interference study results were used to validate the applicability of the developed method for the determination of TDZ in pharmaceutical formulations and urine. All experiments were carried out at room temperature.

\section{Results and Discussion}

\subsection{The Cyclic Voltammetric Investigation of TDZ at 1,4-BQMCPE}

3.1.1. Electrochemical Behaviour of TDZ at 1,4-BQMCPE. The electrochemical behaviour of TDZ was studied using cyclic voltammetry in BRB solution. Figure 1 shows the cyclic voltammograms of $0.5 \mathrm{mM}$ TDZ using CPE (curve (b)) and 1,4-BQMCPE (curve (c)). The voltammograms of CPE and 1,4-BQMCPE in the buffer solution containing TDZ showed a distinct irreversible reductive peak which is absent at the voltammogram recorded in the absence of TDZ (curve (a)).

Comparing the two results, there was excellent improvement in the voltammograms when 1,4-BQMCPE was used. The response in the cyclic voltammograms during the experiment revealed that, in case of unmodified carbon paste electrode, the reduction peak current was observed at $0.680 \mu \mathrm{A}$ while, in the case of the 1,4-BQMCPE, the reduction peak was observed at $1.31 \mu \mathrm{A}$.

3.1.2. Effect of Scan Rate. The effect of scan rate on the electrochemical behaviour of TDZ was also investigated at various scan rates (Figure 2). The redox peak current increased linearly with the square root of the scan rate and the scan rate in the range of $20-200 \mathrm{mV} / \mathrm{s}$. The regression equations can be expressed as $I_{\mathrm{p}}(\mu \mathrm{A})=-3.3422+1.5863 v^{1 / 2}(\mathrm{mV})\left(R^{2}=\right.$ $0.95576)$ and $I_{\mathrm{p}}(\mu \mathrm{A})=2.8545+0.0907 v(\mathrm{mV})\left(R^{2}=0.97953\right)$, which indicated that the electrochemical reaction of TDZ at 1,4-BQMCPE is adsorption controlled process in the selected scan rate range.

The number of electrons transferred on the electrode process $(n)$ for adsorption controlled irreversible process can be estimated using the following equations $[25,26]$ :

$$
\begin{aligned}
I_{\mathrm{PC}} & =\frac{(\alpha n) n^{2} F^{2} A \Gamma \nu}{2.718 R T}, \\
\left|E_{\mathrm{P}}-E_{\mathrm{P} / 2}\right| & =1.85 \frac{R T}{\alpha n F} \mathrm{~V}=\frac{0.048}{\alpha n} \mathrm{~V} \text { at } 25^{\circ} \mathrm{C}, \\
\Gamma & =\frac{\mathrm{Q}}{n F A},
\end{aligned}
$$

where $I_{\mathrm{PC}}$ is cathodic peak current, $v$ is scan rate, $\Gamma$ is surface concentration of the electroactive species $\left(\mathrm{mol} \mathrm{cm}{ }^{-2}\right), A$ is the electrochemical active area $\left(\mathrm{cm}^{2}\right), R$ is the universal gas constant $\left(8.314 \mathrm{~J} \mathrm{~K}^{-1} \mathrm{~mol}^{-1}\right), T(\mathrm{~K})$ is the Kelvin temperature, $F$ is the Faraday constant $\left(96485 \mathrm{C} \mathrm{mol}^{-1}\right), E_{\mathrm{P}}$ is peak potential, $E_{\mathrm{P} / 2}$ is half-peak potential, and $Q$ is charge consumed obtained from integral of peak area. Using (2) $(\alpha n)$ was estimated from (2) to about 2.096 for a scan rate of $100 \mathrm{mV}$. Substituting the $\Gamma$ term of (3) into (1) a new relation for $n$ is obtained:

$$
n=\frac{2.718 I_{\mathrm{PC}} R T}{(\alpha n) F Q \nu} .
$$

Using (4) the number of electrons transferred in the electrode reaction $(n)$ was calculated to be 4.413 which indicated that by approximation four electrons were involved in the reduction of TDZ on the 1,4-BQMCPE, a comparable result with earlier reported works [10]. The value of $\alpha$ is thus calculated to be 0.475 for TDZ still confirming the irreversibility of the reduction of TDZ on 1,4-BQMCPE.

Linear dependence of peak potential $\left(E_{\mathrm{P}}\right)$ against the logarithm of scan rates $(\ln v)$ was observed with a linear equation and correlation coefficient of $E_{\mathrm{P}}(\mathrm{V})=-0.3973 \mathrm{~V}-$ $17.0444 \ln v\left(\mathrm{Vs}^{-1}\right)$ and $R^{2}=0.94117$, respectively (Figure $3(\mathrm{a})$ ). For an irreversible cathodic reaction, the equation used to calculate standard rate constant is [27]

$$
E_{\mathrm{P}}=E^{o}+\frac{R T}{\alpha n F} \ln \left(\frac{R T K_{o}}{\alpha n F}\right)-\frac{R T}{\alpha n F} \ln v,
$$

where $E_{\mathrm{p}}$ is peak potential, $E^{o}$ is the formal potential, $\alpha$ is the transfer coefficient, $K_{o}\left(\mathrm{~s}^{-1}\right)$ is the electrochemical rate constant and the other parameters have their usual meanings.

The value of $E^{o}$ which was obtained from the intercept of the $E_{\mathrm{P}}$ versus $v$ plot (Figure 3(b)) [28] was found to be $-0.4533 \mathrm{~V}$. The value of $K_{o}$ evaluated from the intercept of the 


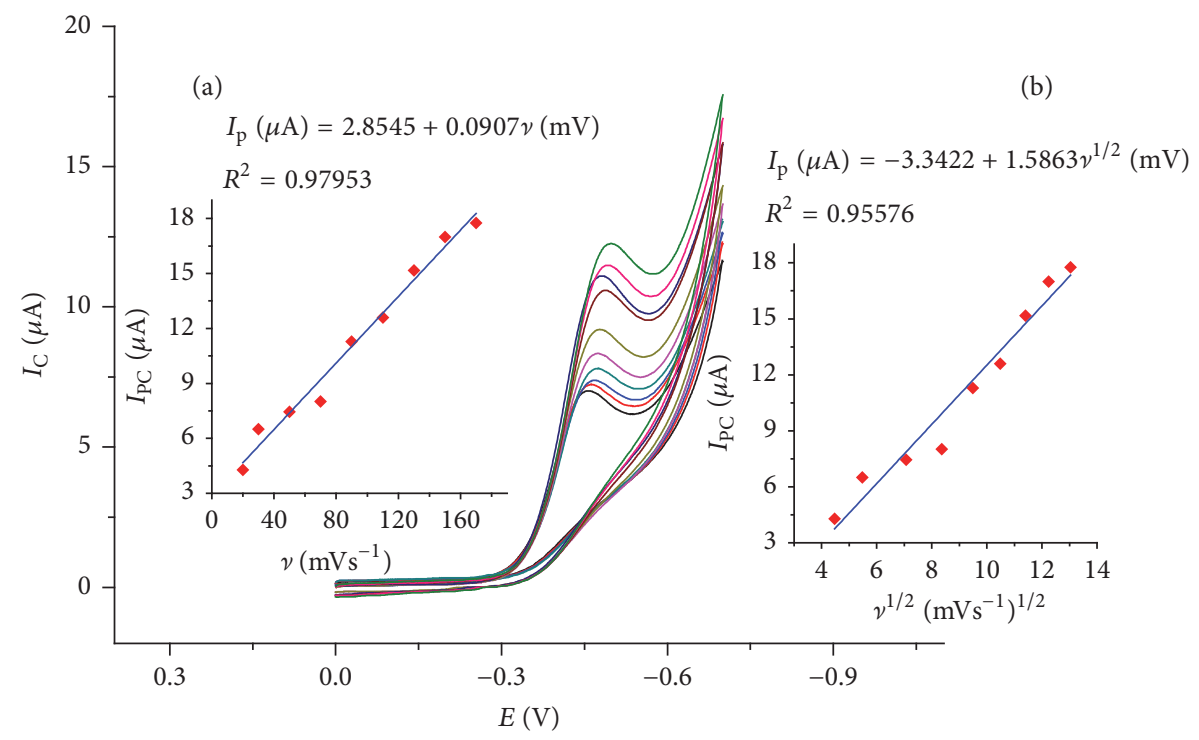

FIGURE 2: Cyclic voltammograms of 1,4-BQMCPE in BRB containing $0.5 \mathrm{mM}$ TDZ at various scan rates $(20,40,60,80,100,125,150,175$, and $200 \mathrm{mV} / \mathrm{s}$, resp.). Inset: plot of variation of $I_{\mathrm{PC}}$ versus (a) scan rate and (b) square root of scan rate.

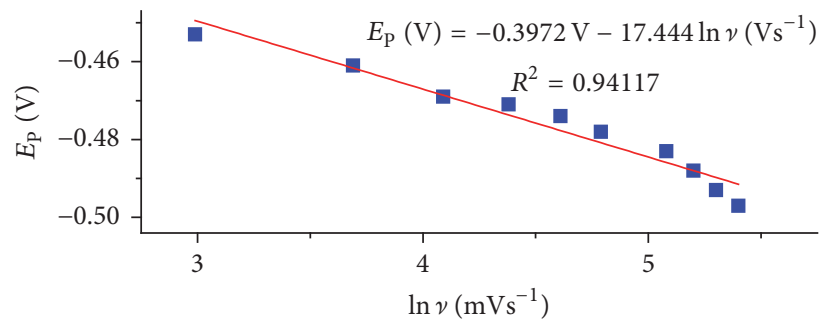

(a)

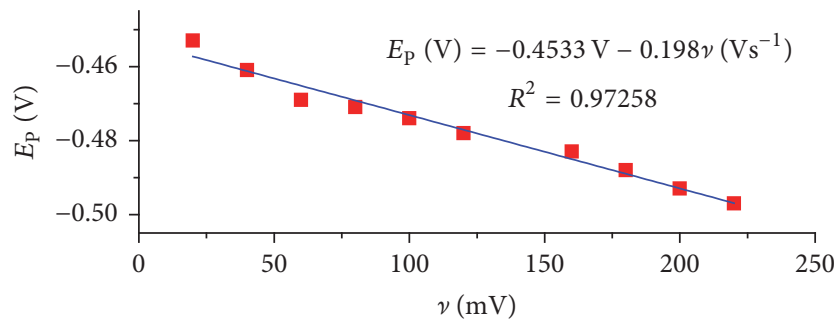

(b)

FIgURE 3: Plot of cathodic peak potential $\left(E_{\mathrm{P}}\right)$ versus (a) ln of scan rate and (b) scan rate.

plot of $E_{\mathrm{P}}$ versus $\ln v$ (Figure 6(a)) as the equation below was calculated to be $8,104.2126 \mathrm{~s}^{-1}$.

$$
E^{0}+\frac{R T}{\alpha n F}\left[\ln \left(\frac{R T K_{o}}{\alpha n F}\right)\right]=-0.3972 \mathrm{~V} .
$$

3.1.3. Effect of $p H$. The effect of $\mathrm{pH}$ on the current response of 1,4-BQMCPE in $0.5 \mathrm{mM}$ of TDZ was investigated in the $\mathrm{pH}$ range from 2.0 to 10.0 by cyclic voltammetry and the results were shown as in Figure 4.

Figure 4 represents only cyclic voltammograms of $0.5 \mathrm{mM} \mathrm{TDZ}$ in the region where its reduction is $\mathrm{pH}$ dependent (pHs 2.0-7.0). A well-defined irreversible cathodic peak was observed in the entire buffer system at the 1,4-BQMCPE. By increasing the $\mathrm{pH}$ the reduction peak potential of TDZ shifts to more negative potentials up to $\mathrm{pH} 7.0$ which is an indication of proton participation in the reduction of TDZ at acidic medium. But from $\mathrm{pH} 7.0$ and above the peak potential remained constant which indicated the absence of protons during the reduction of TDZ at 1,4-BQMCPE in neutral and basic media.

The results revealed that voltammetric responses were strongly $\mathrm{pH}$ dependent in the acidic region in contrast to the neutral and alkaline mediums which was in agreement with

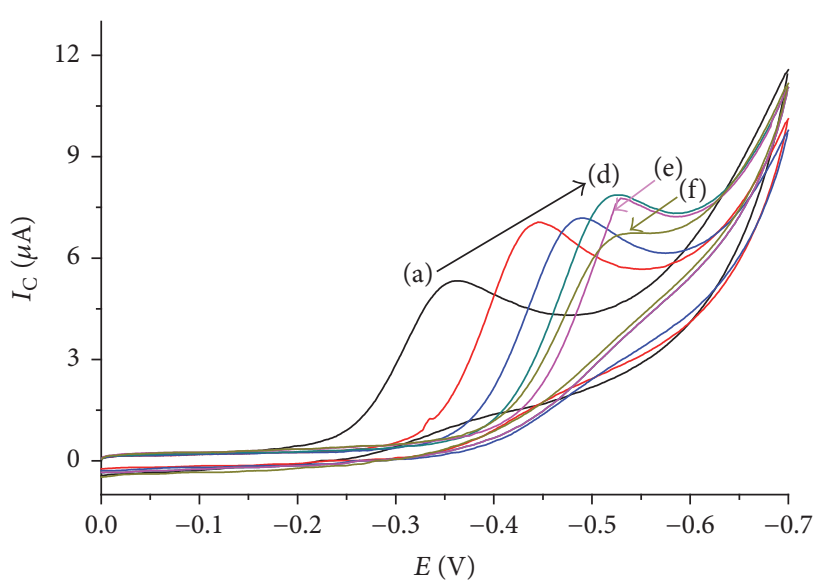

FIgURE 4: Cyclic voltammograms of $0.5 \mathrm{mM}$ TDZ in BRB solution of different $\mathrm{pH}$ values ((a)-(f): 2.0, 3.0, 4.0, 5.0, 6.0, and 7.0, resp.). Scan rate: $100 \mathrm{mV} \mathrm{s}^{-1}$.

most of the electrochemical methods reported $[7,9,10]$. A peak potential independent of $\mathrm{pH}$ in the neutral and alkaline medium could be attributed to the unavailability of protons that promote the reduction of TDZ at pHs larger than its pka value. 


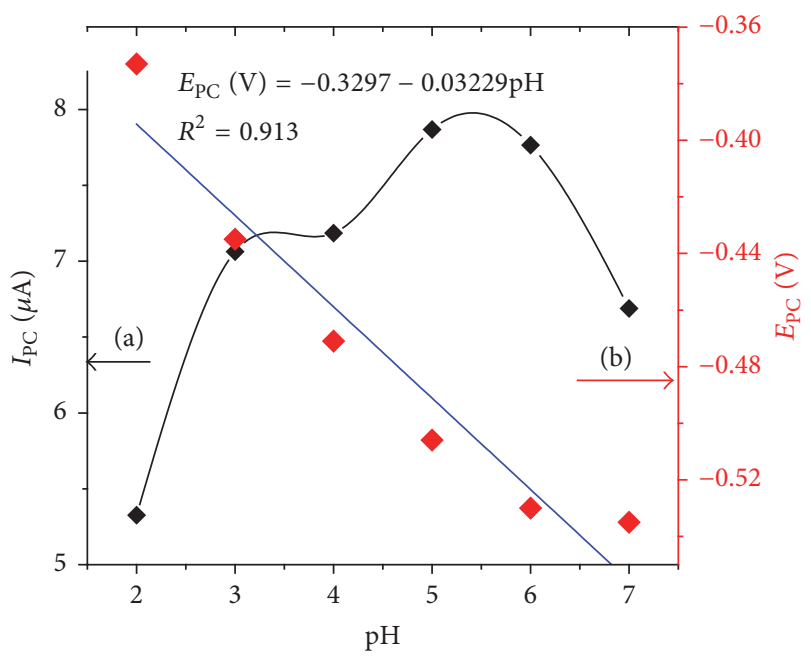

FIGURE 5: Plot of reductive (a) peak current and (b) peak potential versus $\mathrm{pH}$ for $0.5 \mathrm{mM}$ TDZ in $0.1 \mathrm{M}$ BRB SOLUTION of different $\mathrm{pH}$ values at 1,4-BQMCPE. Scan rate: $100 \mathrm{mV} / \mathrm{s}$.

The reduction peak current increased sharply with an increasing $\mathrm{pH}$ value from 2 to 5 and then decreased when further increasing solution $\mathrm{pH}$. Considering the determination sensitivity, $\mathrm{pH} 5$ was chosen for the subsequent analytical experiments.

Since there was an indication of participating of protons during reduction of TDZ in the acidic medium, a linear relationship between the peak potential and solution $\mathrm{pH}$ (up to $\mathrm{pH} 7$ ) (Figure 5(b)) with a linear regression equation and correlation coefficient of $E_{\mathrm{P}}(\mathrm{V})=-0.3297-0.03229 \mathrm{pH}$ and $R^{2}=$ 0.913 , respectively, was obtained. A slope of $0.03229 \mathrm{~V} / \mathrm{pH}$ typically suggested that the number of protons taking part in the electrode reaction is equal to the number of electrons that participated in the rate determining step. Since the number of electrons that participated are already calculated in the previous discussion to be four, it is now possible to suggest that the irreversible reduction of TDZ at 1,4-BQMCPE involves four electrons and four protons (Scheme 2).

3.2. Differential Pulse Voltammetric Investigation. The electrochemical reduction of TDZ at 1,4-BQMCPE was studied using differential pulse voltammetry. No peak was observed at the voltammogram of 1,4-BQMCPE in buffer solution while there was an irreversible reductive peak in the presence of TDZ (Figure 6).

Since the kinetics of the reduction of TDZ at 1,4BQMCPE are adsorption controlled, the accumulation $\left(E_{\text {acc }}\right)$ and accumulation time $\left(t_{\mathrm{acc}}\right)$ were optimized. Moreover, method parameters such as scan rate, pulse amplitude, and modifier composition were optimized.

\subsubsection{Optimization of DPV Parameters for TDZ Determination}

DPV Pulse Amplitude and Scan Rate. The effect of differential pulse amplitude and scan rate on the peak current of $0.5 \mathrm{mM}$

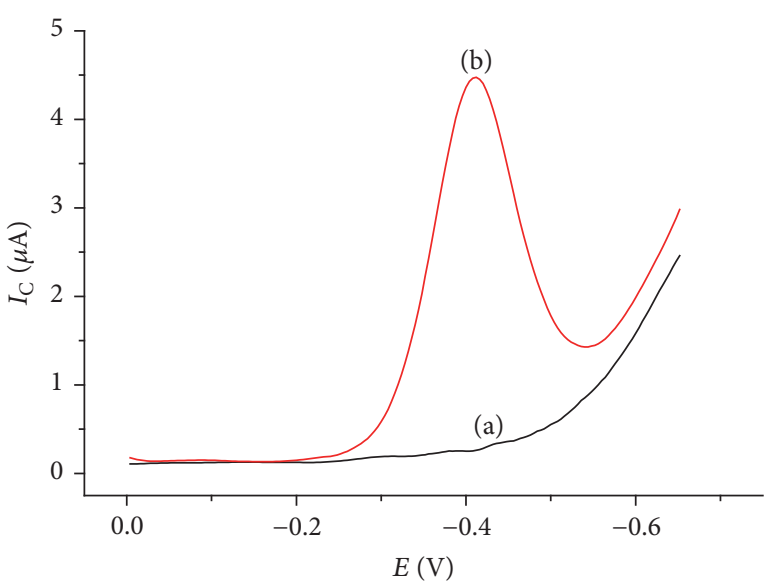

FIGURE 6: Differential pulse voltammograms of 1,4-BQMCPE in $\mathrm{pH}$ 5.0 BRB solution containing (a) no TDZ and (b) $0.5 \mathrm{mM} \mathrm{TDZ}$.

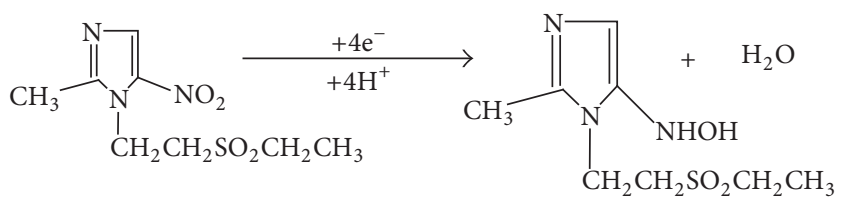

SCHEME 2: The proposed reduction reaction mechanism of tinidazole on 1,4-BQMCPE.

TDZ in pH 5 BRB solutions was studied in the range of 20 to $55 \mathrm{mV}$ and $15-40 \mathrm{mV} / \mathrm{s}$, respectively. As shown in Figure 7, upon increasing both amplitude and scan rate, a linear increase in the peak current was observed accompanied by peak broadening in particular when the amplitude was greater than $45 \mathrm{mV}$. Thus, $45 \mathrm{mV}$ of amplitude and $30 \mathrm{mV} / \mathrm{s}$ of scan rate were chosen as optimum values.

Accumulation Potential $\left(E_{\text {acc }}\right)$ and Accumulation Time $\left(t_{\text {acc }}\right)$. The effect of accumulation potential $\left(E_{\mathrm{acc}}\right)$ on the peak current for $0.5 \mathrm{mM}$ TDZ was examined in the range of -50 to $-400 \mathrm{mV}$. The peak current for TDZ initially increased when the accumulation potential was increased and reaches maximum at $-300 \mathrm{mV}$ as shown in Figure 9. Therefore, the accumulation potential $\left(E_{\mathrm{acc}}\right)$ of $-300 \mathrm{mV}$ was chosen as the optimum accumulation potential for further work.

The effect of accumulation time $\left(t_{\text {acc }}\right)$ on the peak current of $0.5 \mathrm{mM}$ TDZ at a potential of $-300 \mathrm{mV}$ was also investigated. The variation of accumulation time between 5 and $45 \mathrm{~s}$ at an accumulation potential of $-300 \mathrm{mV}$ showed that the peak current increased with the increase in accumulation time up to $30 \mathrm{~s}$ and then almost leveled off (Figure 8(b)). The increase of peak current with increase in accumulation time indicated that TDZ can be accumulated at the surface of the 1,4-BQMCPE. The leveling off peak current after $30 \mathrm{~s}$ could be ascribed to the saturation of the surface of the electrode. So the accumulation time of $30 \mathrm{~s}$ was selected as an optimum accumulation time for further experiments.

Effect of Modifier Composition. When the content of benzoquinone was increased from $0 \%$ to $15 \%$ (w/w), as can be seen 


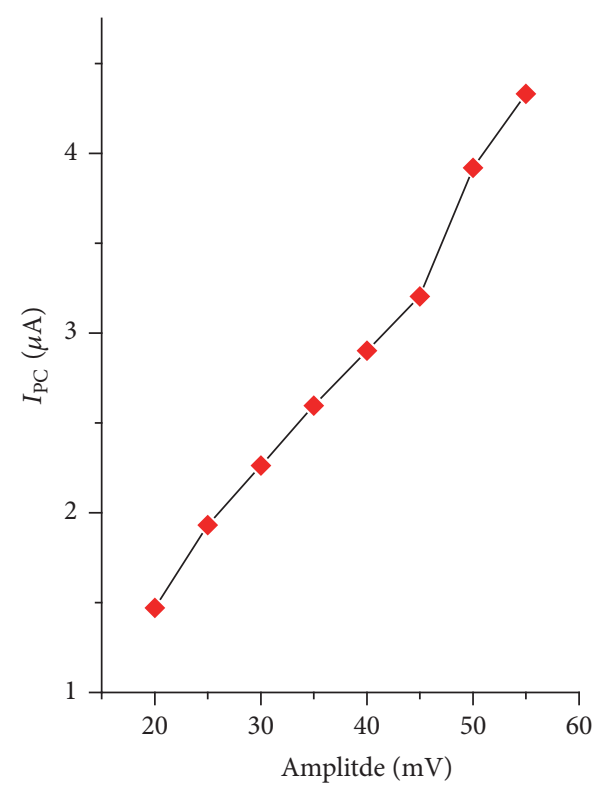

(a)

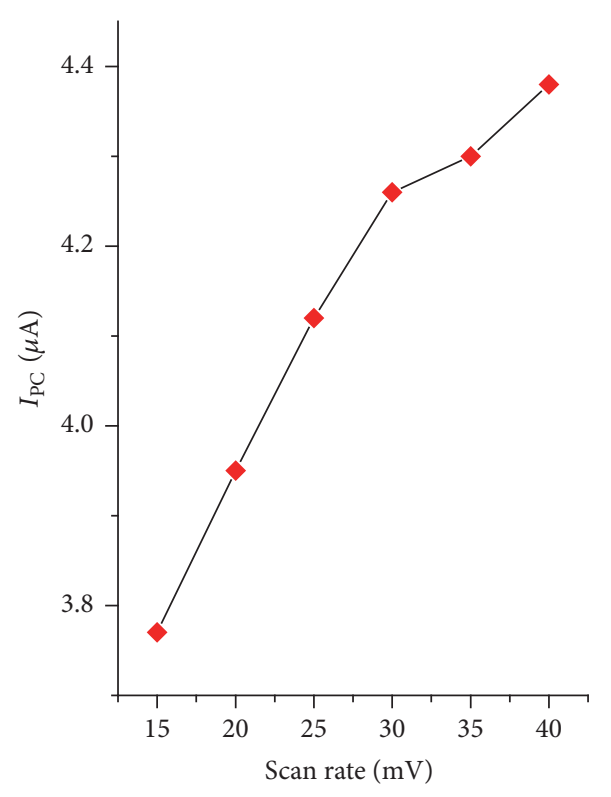

(b)

FIGURE 7: Plot of differential pulse voltammetric peak current response of 1,4-BQMCPE for 0.5 mM tinidazole (a) versus differential pulse amplitude and (b) versus scan rate at $45 \mathrm{mV}$ of amplitude.

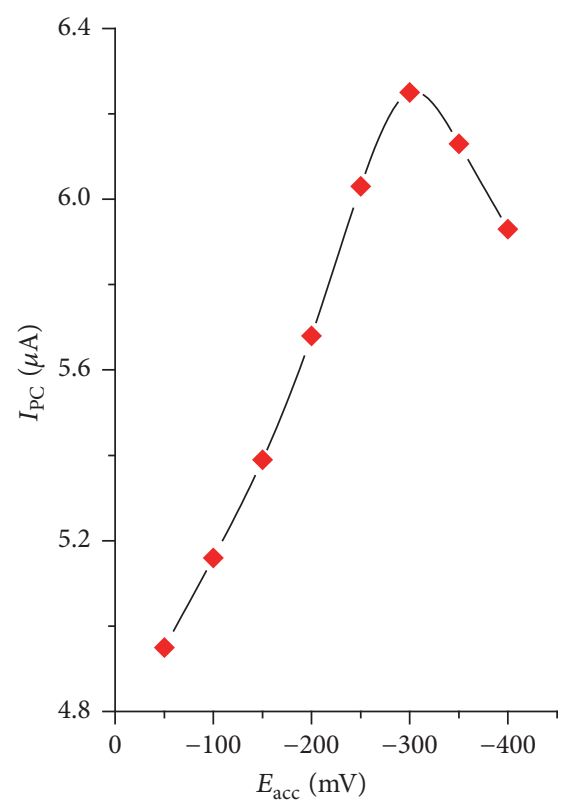

(a)

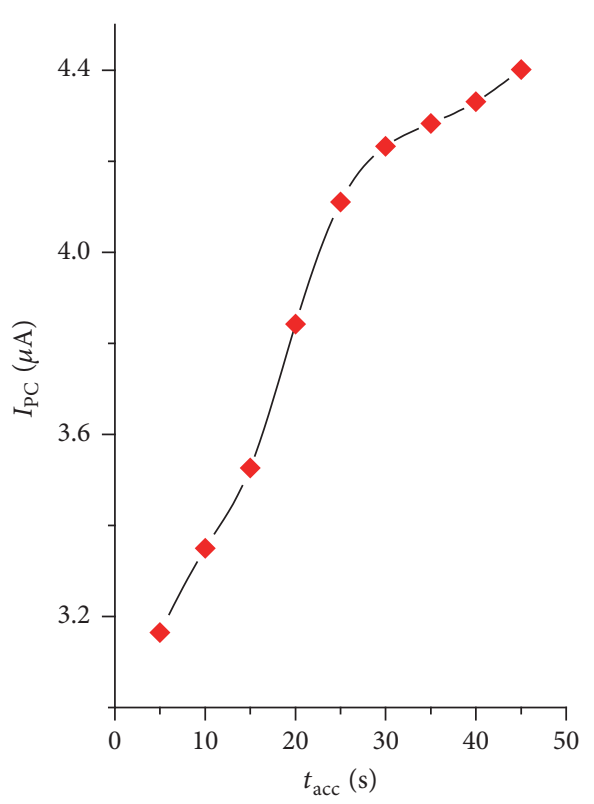

(b)

FIGURE 8: Plot of differential pulse voltammetric peak current response of 1,4-BQMCPE for $0.5 \mathrm{mM}$ TDZ versus (a) accumulation potential and (b) accumulation time at $E_{\text {acc }}=-300 \mathrm{mV}$.

from Figure 9, the peak current increased with increasing the modifier composition from $0 \%$ to to $20 \%(\mathrm{w} / \mathrm{w})$. A peak current decrease was observed at modifier composition higher than $20 \%(\mathrm{w} / \mathrm{w})$ and, hence, a modifier composition of $20 \%(\mathrm{w} / \mathrm{w})$ was taken as the optimum modifier composition throughout the present work.
Optimum Experimental Conditions. The effects of experimental parameters have been studied to obtain optimum experimental conditions for differential pulse Voltammetric determination of TDZ at 1,4-BQMCPE. The optimum parameters used for the experiment are summarized in Table 1. 
TABLE 1: Optimum values of the experimental parameters for the determination of TDZ by differential pulse voltammetric (DPV) technique at 1,4-BQMCPE.

\begin{tabular}{lc}
\hline Parameter & Optimized value \\
\hline pH of the buffer solution & 5 \\
DPV pulse amplitude $(\mathrm{mV})$ & 45 \\
DPV Scan rate $(\mathrm{mV} / \mathrm{s})$ & 30 \\
Accumulation potential $(\mathrm{mV})$ & -300 \\
Accumulation time $(\mathrm{s})$ & 30 \\
Effect of modifier composition $(\%(\mathrm{w} / \mathrm{w}))$ & 20 \\
\hline
\end{tabular}

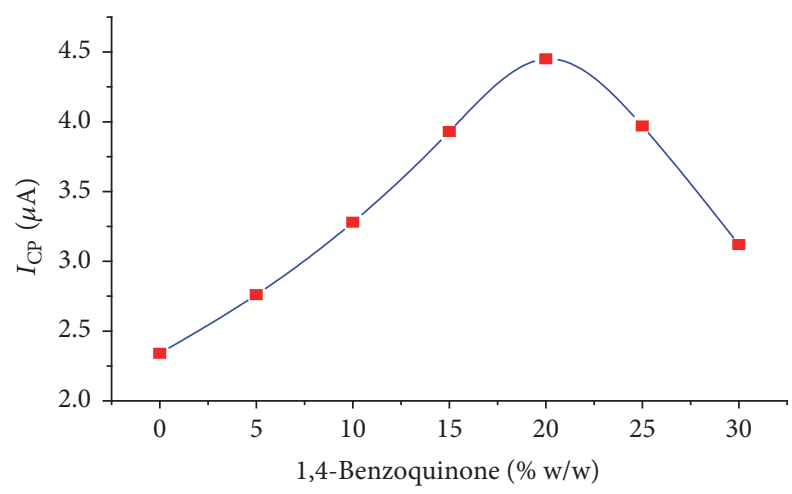

FIGURE 9: The effect of amount of benzo quinone (modifier) on the reduction peak current $0.5 \mathrm{mM}$ tinidazole. Amplitude $=45 \mathrm{mV}$. Scan rate $=30 \mathrm{mV} / \mathrm{s}$.

3.2.2. Calibration Plot for TDZ. Under the optimized experiment conditions, the calibration curve for TDZ in $\mathrm{pH} 5.0$ $\mathrm{BRB}$ at 1,4-BQMCPE was characterized by DPV. As can be seen (Figure 10 inset), the reduction peak current $\left(I_{\mathrm{PC}}\right)$ was proportional to the concentration of TDZ in the range from 1 to $300 \mu \mathrm{M}$. The calibration curve for ten average data points ( $n=10$ ) was found to be linear with $R=0.99486$ and a regression equation of $I_{\mathrm{PC}}(\mu \mathrm{A})=0.19958+0.02657 \mathrm{C}(\mu \mathrm{M})$. The limit of detection and limit of quantification were calculated to be $1.10 \times 10^{-7}$ and $3.77 \times 10^{-7}$, respectively.

The detection performance of 1,4-BQMCPE was compared with other electrodes and the results are listed in Table 2. As can be seen from the table, the developed method, which used a very cheap and easily available electrode, showed a relatively comparable limit of detection and linear range even with the methods used which are definitely much more expensive electrodes like SWCNT/GCE.

3.2.3. Reproducibility and Stability of 1,4-BQMCPE. In this experiment, reproducibility was investigated by considering three modified electrodes prepared independently by taking triplicate measurements using the three electrodes. The reproducibility expressed in relative standard deviation was found to be $3.44 \%$ for $0.5 \mu \mathrm{M}$ TDZ solution showing excellent reproducibility of the method.

The 1,4-BQMCPE showed high stability. As it is shown during the experiment, there has been no significant difference in the peak current responses for the same electrode and the same standard solutions over a period of one month.

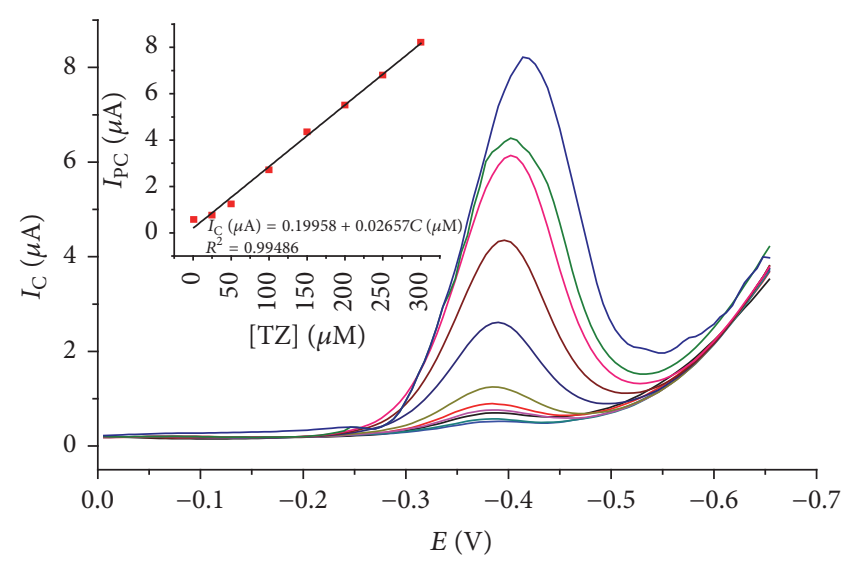

FIGURE 10: DPV of 1,4-BQMCPE (corrected for background) in $\mathrm{pH}$ 7 BRB solution of different concentrations of $\operatorname{TDZ}(1,5,25,50,100$, $150,200,250,350,400,450$, and $500 \mu \mathrm{M}$, resp.). Inset: calibration curve of peak current $\left(I_{\mathrm{PC}}\right)$ versus concentration $(C)$ of TDZ in $\mathrm{BRB}$ solution on 1,4-BQMCPE.

3.2.4. Determination of TDZ in Pharmaceutical Tablets. The applicability of 1,4-BQMCPE for the determination of TDZ was demonstrated by applying it to determine the TDZ content in some pharmaceutical tablets. These samples were prepared as described in Section 2.2.2. Briefly, tablets from each brand (APF and EPHARM) were weighed and powdered. An amount corresponding to a stock solution of $0.01 \mathrm{M}$ concentration was weighed and transferred into a $100 \mathrm{~mL}$ flask and completed to the volume with pH 5 BRB solution. Finally, 50 and $90 \mu \mathrm{M}$ tablet sample solutions for each brand were prepared from the corresponding stock solution. Differential pulse voltammograms were recorded following the outlined voltammetric procedure and optimized conditions as described earlier. Analyses were done using triplicate measurements and the mean values were recorded. The determination of TDZ in these samples was carried out according to the linear regression equation formulated for the calibration curve.

Table 3 presents the summary of the analyses on the TDZ composition of the two tablet brands. The tablet formulations for the collected two brands being $500 \mathrm{mg}$ of TDZ per tablet, the amount of TDZ found using the developed method ranged between 479.845 and $491.95 \mathrm{mg}$ per tablet showing deviation of the experimental result from the theoretical value. Lower levels of TDZ in tablets than prescribed value may be due to the possible mass loss of TDZ during preparation or some TDZ degradation during storage or this can be due to originally lower levels of TDZ in the tablets.

3.2.5. Recovery Analyses. The applicability of the developed method for the determination of TDZ in real samples was further evaluated by recovery analyses of spiked standard TDZ in the two brand tablet samples. The differential pulse voltammograms for $90 \mu \mathrm{M}$ tablet samples of each tablet brand, each spiked with the same amount of standard TDZ ( $5 \mathrm{mg})$, were recorded. The $\%$ recoveries were calculated taking into consideration the amounts previously detected 
TABLE 2: Comparison between the developed method and other reported methods.

\begin{tabular}{|c|c|c|c|c|}
\hline Electrode & Method & Linear range $(\mathrm{M})$ & Detection limit $(\mathrm{M})$ & Ref. \\
\hline SWNT/GCE & DPV & $5 \times 10^{-8}-4 \times 10^{-5}$ & $1 \times 10^{-8}$ & [7] \\
\hline HMDE & DPP & $2 \times 10^{-6}-1.1 \times 10^{-3}$ & $9.7 \times 10^{-7}$ & [8] \\
\hline GCE & DPV & $10^{-7}-10^{-9}$ & $3 \times 10^{-10}$ & [9] \\
\hline $\mathrm{CPE}$ & DPV & $5 \times 10^{-6}-2 \times 10^{-4}$ & $5.06 \times 10^{-7}$ & {$[10]$} \\
\hline 1,4-BQMCPE & DPV & $10^{-6}-5 \times 10^{-4}$ & $1.1 \times 10^{-7}$ & This work \\
\hline
\end{tabular}

TABLE 3: Amount of TDZ detected in two brands of tablets using the developed method.

\begin{tabular}{|c|c|c|c|c|c|c|}
\hline \multirow{2}{*}{ Tablet } & \multirow{2}{*}{ Solution } & \multirow{2}{*}{ Expected $(\mu \mathrm{M})$} & \multicolumn{2}{|c|}{ Detected $^{*}$} & \multirow{2}{*}{ Labeled value (mg/tablet) } & \multirow{2}{*}{ Measured (\%) } \\
\hline & & & In $\mu \mathrm{M}$ & $\mathrm{mg} /$ tablet & & \\
\hline \multirow{2}{*}{ APF } & a & 50 & 48.174 & 481.74 & 500 & 96.35 \\
\hline & $\mathrm{b}$ & 90 & 86.372 & 479.845 & 500 & 95.97 \\
\hline \multirow{2}{*}{ EPHARM } & $\mathrm{a}$ & 50 & 49.195 & 491.95 & 500 & 98.39 \\
\hline & $\mathrm{b}$ & 90 & 87.538 & 486.32 & 500 & 97.26 \\
\hline
\end{tabular}

${ }^{*}$ Mean of triplicate measurements.

TABLE 4: Percentage recovery of TDZ from pharmaceutical tablets.

\begin{tabular}{lccccc}
\hline Tablet & Present TDZ $(\mathrm{mg})$ & Added TDZ $(\mathrm{mg})$ & Expected TDZ $(\mathrm{mg})$ & Found $(\mathrm{mg})$ & Recovery $(\%) \pm \%$ RSD \\
\hline APF & 0.534 & 5 & 5.534 & $5.396 \pm 0.0023$ & $97.51 \pm 3.11$ \\
EPHARM & 0.541 & 5 & 5.541 & $5.399 \pm 0.0027$ & $97.44 \pm 2.71$ \\
\hline
\end{tabular}

${ }^{*}$ Mean of double measurements.

TABLE 5: Percentage recovery of TDZ from human urine sample solutions.

\begin{tabular}{lccccc}
\hline Tablet & Present TDZ $(\mathrm{mg})$ & Added TDZ $(\mathrm{mg})$ & Expected TDZ $(\mathrm{mg})$ & Detected $(\mathrm{mg})$ & Recovery $(\%) \pm \%$ RSD \\
\hline APF & 0.556 & 5 & 5.556 & 5.299 & $95.37 \pm 2.08$ \\
EPHARM & 0.556 & 5 & 5.556 & 5.384 & $96.91 \pm 3.29$ \\
\hline
\end{tabular}

in the $90 \mu \mathrm{M}$ tablet samples. The recovery results are summarized in Table 4 . The results confirmed the potential applicability of the developed method for TDZ analyses in real samples. As can be seen from Table 4, the maximum relative standard deviation (RSD) recorded for a duplicate measurement was 3.11 showing the reproducibility of the response of the electrode. The results obtained using the proposed method are almost comparable to or even better than the results obtained by a method which used a very expensive single-wall carbon nanotubes coated glassy carbon electrode which has a maximum RSD of 4.6 [7].

3.2.6. Determination of TDZ in Human Urine. Approximately $20-25 \%$ of the administered dose of TDZ is excreted in the urine mainly as unchanged drug [29]. Therefore considering this the applicability of 1,4-BQMCPE for the determination of TDZ was also investigated by the determination of TDZ in human urine solution.

Taking into consideration the amount previously detected, sample solutions with concentration of $90 \mu \mathrm{M}$ in urine samples were prepared using the diluted human urine (as described in Section 2.2.3) for both TDZ tablet brands. Under the optimized parameters, DPV was employed to determine the reductive current response for the urine samples at 1,4-BQMCPE and the results summarized in Table 5 were obtained.

3.2.7. Interference Analyses. Different potential interferents were taken to study selectivity of the method for TDZ. For the interference studies, drugs which could be present in the TDZ tablet (omeprazole and ciprofloxacin), drug which have structural similarities with TDZ (metronidazole), and ingredients (excipients) of TDZ drug were selected.

As can be seen from Table 6, the presence of metronidazole showed positive interference on the peak current for TDZ and the peak current change was greater than 5\%, a comparable result with other reports $[7,30]$. This is because they contain the same reductive groups that can be reduced near the potentials of TDZ [7]. But the presence of the other selected interferents did not significantly affect the peak current response for the TDZ and the change in peak current was less than $5 \%$.

\section{Conclusion}

1,4-Benzoquinone modified carbon paste electrode was successfully applied for the voltammetric determination of TDZ in real pharmaceutical tablets and human urine. The 
TABLE 6: Interference study of TDZ with different selected drugs.

\begin{tabular}{lccc}
\hline & $\begin{array}{c}\text { Concentration } \\
(\text { in } \mu \mathrm{M})\end{array}$ & $\begin{array}{c}\text { Recorded } \\
\text { Signal }\left(I_{\mathrm{P}} / \mu \mathrm{A}\right)\end{array}$ & 5.512 \\
Change $(\%)$ \\
Interferents added & 200 & & \\
$\quad$ Cellulose & & 5.501 & 0.199 \\
Magnesium striate & 80 & 5.394 & 2.141 \\
Titanium dioxide & 80 & 5.407 & 1.905 \\
Polyethylene glycol & 80 & 5.351 & 2.921 \\
Metronidazole & 80 & 6.084 & 10.377 \\
Omeprazole & 80 & 5.473 & 0.708 \\
Ciprofloxacin & 80 & 5.297 & 3.900 \\
\hline
\end{tabular}

proposed method provides a sensitive and simple approach for determination of TDZ in real pharmaceutical tablets and human urine. Because of its very low limits of detection and quantification, relative to the previously reported works which have used expensive electrodes, the proposed method could be applied in clinical laboratories and pharmacokinetic studies even in a complex matrix system like pharmaceutical formulations.

\section{Conflicts of Interest}

The authors declare that there are no conflicts of interest regarding the publication of this paper.

\section{References}

[1] D. I. Edwards, "Nitroimidazole drugs-action and resistance mechanisms I. Mechanisms of action," Journal of Antimicrobial Chemotherapy, vol. 31, no. 1, pp. 9-20, 1993.

[2] L. J. Dickey, M. D. Nailor, and J. D. Sobel, "Guidelines for the treatment of bacterial vaginosis: Focus on tinidazole," Therapeutics and Clinical Risk Management, vol. 5, no. 1, pp. 485-489, 2009.

[3] K. Madhuri, M. Senthil Kumar, and L. Kalyani, "A Review on Tinidazole," IJPCBS, vol. 1, no. 1, pp. 38-42, 2011.

[4] J. N. Scragg, C. J. Rubidge, and E. M. Proctor, "Tinidazole in treatment of acute amoebic dysentery in children," Archives of Disease in Childhood, vol. 51, no. 5, pp. 385-387, 1976.

[5] R. N. Pawar, S. N. Chavan, and M. D. Menon, "Development, characterization and evaluation of tinidazole nanosuspension for treatment of amoebiasis," Journal of Nanomedicine \& Nanotechnology, vol. 7, no. 6, pp. 1-4, 2016.

[6] P. V. Rege, P. A. Sathel, and V. S. Salvi, "A simple electroanlytical method for simultaneous determination of norfloxacin and tinidazole from combined pharmaceutical drug formulation," International Journal of ChemTech Research, vol. 3, no. 3, pp. 1213-1219, 2011.

[7] C. Yang, "Voltammetric determination of tinidazole using a glassy carbon electrode modified with single-wall carbon nanotubes," Analytical Sciences, vol. 20, no. 5, pp. 821-824, 2004.

[8] V. S. Salvi, P. A. Sathe, and P. V. Rege, "Determination of tinidazole and ciprofloxacin hydrochloride in single formulation tablet using differential pulse polarography," Journal of Analytical \& Bioanalytical Techniques, vol. 1, no. 3, pp. 1-3, 2010.
[9] H. M. Elqudaby, G. G. Mohamed, F. A. Ali, and S. M. Eid, "Validated voltammetric method for the determination of some antiprotozoa drugs based on the reduction at an activated glassy carbon electrode," Arabian Journal of Chemistry, vol. 6, no. 3, pp. 327-333, 2013.

[10] A. Taye and M. Amare, "Voltammetric determination of tinidazole in pharmaceutical tablets using carbon paste electrode," Bulletin of the Chemical Society of Ethiopia, vol. 30, no. 1, pp. $1-12,2016$.

[11] L. O. Okunrobo, "Titrimetric and spectrophotometric determination of tinidazole tablets," World Journal of Chemistry, vol. 2, no. 2, pp. 63-66, 2007.

[12] K. Basavaiah, P. Nagegowda, and U. Chandrashekar, "Determination of tinidazole by potentiometry, spectroscopy and high performance liquid chromatography," Indian Journal of Chemical Technology, vol. 12, no. 3, pp. 273-280, 2005.

[13] R. K. Maheshwari, M. S. Rajput, and S. Sinha, "Ecofriendly spectrophotometric estimation of tinidazole in tablets using lignocaine hydrochloride as a hydrotropic solubilizing agent," Asian Journal of Pharmaceutics, vol. 3, no. 4, pp. 319-321, 2009.

[14] L. Singh and S. Nanda, "Method for determination of tinidazole using direct UV-visible spectrophotometry and differential spectrophotometry in pure and tablet dosage forms," East and Central African Journal of Pharmaceutical Sciences, vol. 14, pp. 75-80, 2011.

[15] N. A. F. Alhemiary and M. H. A. Saleh, "Spectrophotometric determination of tinidazole using promethazine and ethyl vanillin reagents in pharmaceutical preparations," Der Pharma Chemica, vol. 4, no. 6, pp. 2152-2160, 2012.

[16] F. Belal, M. K. Sharaf El-Din, M. I. Eid, and R. M. ElGamal, "Micellar HPLC and derivative spectrophotometric methods for the simultaneous determination of fluconazole and tinidazole in pharmaceuticals and biological fluids," Journal of Chromatographic Science (JCS), vol. 52, no. 4, pp. 298-309, 2014.

[17] G. M. Hadad, R. A. Abdel Salam, and M. M. Elkhoudarya, "Simultaneous Determination of Clarithromycin, Tinidazole and Omeprazole in Helicure Tablets Using Reflectance NearInfrared Spectroscopy with the Aid of Chemometry," Pharmaceutica Analytica Acta, vol. 6, no. 4, 2015.

[18] K. Rajnarayana, M. R. Chaluvadi, V. R. Alapati, S. R. Mada, G. Jayasagar, and D. R. Krishna, "Validated HPLC method for the determination of tinidazole in human serum and its application in a clinical pharmacokinetic study," Pharmazie, vol. 57, no. 8, pp. 535-537, 2002.

[19] K. Pasha, A. Ali, S. Bana, and S. Humair, "Reverse phase HPLC method for the analysis of Tinidazole in pharmaceutical 
dosage form \& bulk drug," International Journal of Pharmacy and Pharmaceutical Sciences, vol. 2, no. 2, pp. 46-47, 2010.

[20] M. M. Sebaiy, A. A. El-Shanawany, S. M. El-Adll, L. M. Abdel-Azizl, and H. A. Hashem, "Rapid RP-HPLC Method for Simultaneous Estimation of Norfloxacin and Tinidazole in Tablet Dosage Form," Asian Journal of Pharmaceutical Analysis, vol. 1, no. 4, pp. 79-84, 2011.

[21] Y. Kulsum, C. Rahul Reddy, M. Kanaka Durga, and M. Padmalatha, "A simple and validated RP-HPLC method for the simultaneous estimation of tinidazole and ciprofloxacin in bulk and pharmaceutical dosage forms," International Journal of Research and Development in Pharmacy \& Life Sciences, vol. 2, no. 1, pp. 238-243, 2013.

[22] T. Sirisha, B. M. Gurupadayya, and S. Sridhar, "Simultaneous determination of ciprofloxacin and tinidazole in tablet dosage form by reverse phase high performance liquid chromatography," Tropical Journal of Pharmaceutical Research, vol. 13, no. 6, pp. 981-987, 2014.

[23] M. M. Radhi, "Fabrication and characterization of grafted polymer electrode self modification with activated carbon," International Journal of Industrial Chemistry, vol. 7, no. 1, pp. 103-108, 2016.

[24] M. Aklilu, M. Tessema, and M. Redi-Abshiro, "Indirect voltammetric determination of caffeine content in coffee using 1,4benzoquinone modified carbon paste electrode," Talanta, vol. 76, no. 4, pp. 742-746, 2008.

[25] A. J. Bard and L. R. Faulkner, Electrochemical methods, Fundamentals and Applications, John Wiley \& Sons, New Jersey, NJ, USA, 2nd edition, 2001.

[26] J. Wang, Analytical Electrochemistry, John Wiley \& Sons, New Jersey, NJ, USA, 3rd edition, 2006.

[27] E. Laviron, "General expression of the linear potential sweep voltammogram in the case of diffusionless electrochemical systems," Journal of Electroanalytical Chemistry, vol. 101, no. 1, pp. 19-28, 1979.

[28] L. Fotouhi, M. Fatollahzadeh, and M. M. Heravi, "Electrochemical behavior and voltammetric determination of sulfaguanidine at a glassy carbon electrode modified with a multi-walled carbon nanotube," International Journal of Electrochemical Science, vol. 7, no. 5, pp. 3919-3928, 2012.

[29] I. Nilsson-Ehle, B. Ursing, and P. Nilsson-Ehle, "Liquid chromatographic assay for metronidazole and tinidazole: Pharmacokinetic and metabolic studies in human subjects," Antimicrobial Agents and Chemotherapy, vol. 19, no. 5, pp. 754-760, 1981.

[30] Y. Nikodimos and M. Amare, "Electrochemical Determination of Metronidazole in Tablet Samples Using Carbon Paste Electrode," Journal of Analytical Methods in Chemistry, vol. 2016, Article ID 3612943, pp. 1-7, 2016. 

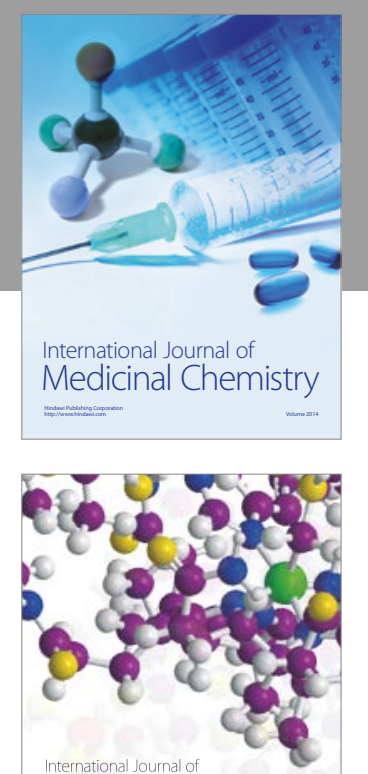

Carbohydrate Chemistry

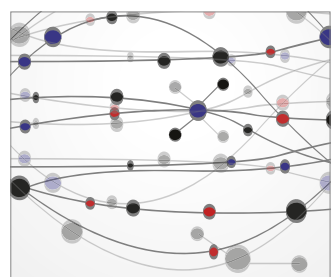

The Scientific World Journal
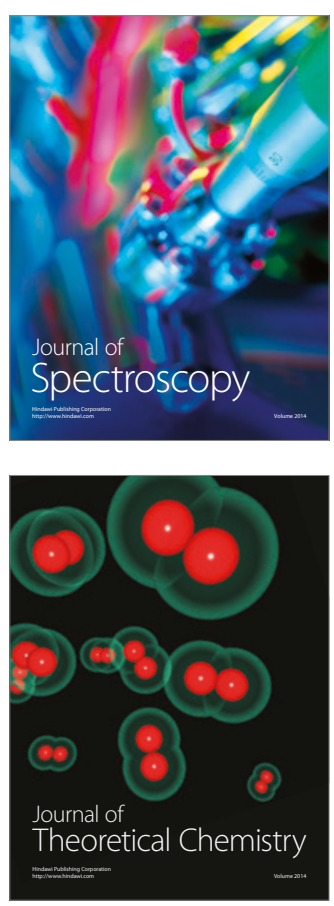
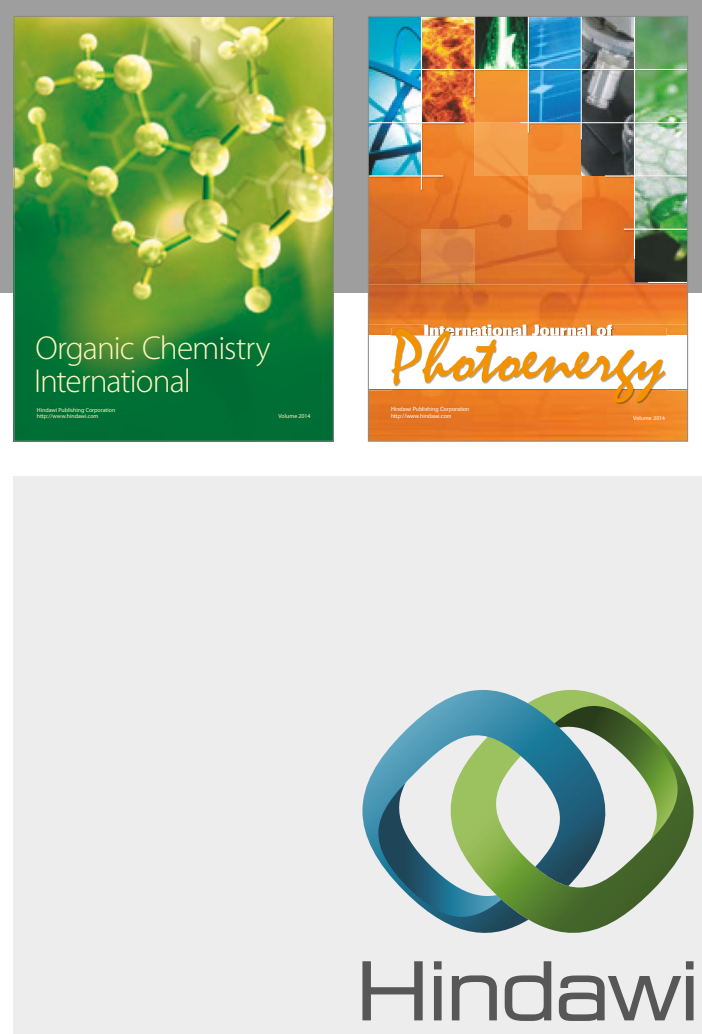

Submit your manuscripts at

https://www.hindawi.com

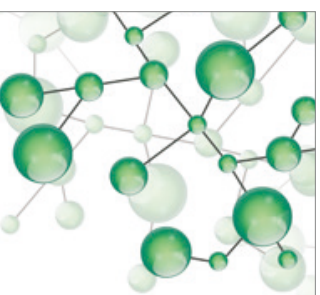

International Journal of

Inorganic Chemistry

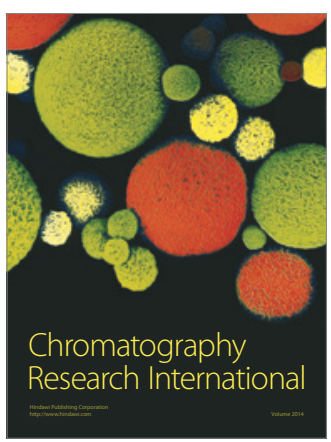

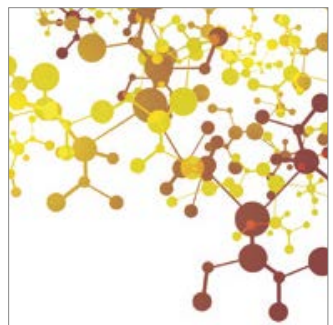

Applied Chemistry
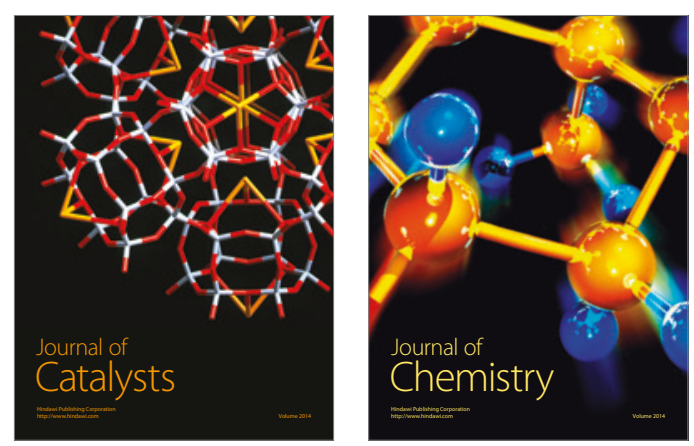
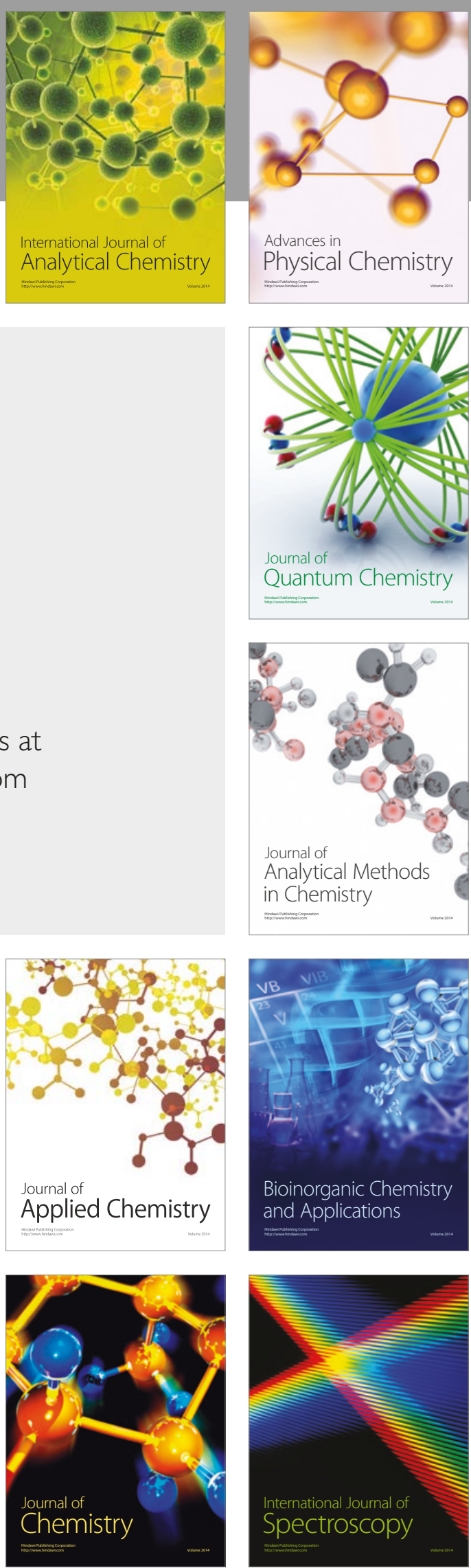